\title{
WORKSHOP PENGGUNAAN SOFTWARE GEOGEBRA SEBAGAI MEDIA PEMBELAJARAN MATEMATIKA BAGI GURU SD/MI
}

\author{
Megita Dwi Pamungkas ${ }^{1}$, Fadhilah Rahmawati ${ }^{2}$ \\ ${ }^{1,2}$ Program Studi Pendidikan Matematika, FKIP, Universitas Tidar \\ Email : megitadwip@untidar.ac.id
}

\begin{abstract}
ABSTRAK
Kegiatan pengabdian pada masyarakat ini dilatarbelakangi adanya permasalahan pada mitra, yaitu kebanyakan guru-guru belum pernah menggunakan aplikasi atau media pembelajaran matematika yang menarik dan inovatif. Mereka sebagian besar mengajar dengan berceramah dan berdiskusi di kelas. Walaupun sudah menggunakan alat peraga, namun dirasa kurang menarik dan inovatif. Diperlukan adanya media pembelajaran yang dapat memfasilitasi guru SD/MI dalam kegiatan mengajar di kelas agar siswa tertarik dan antusias saat belajar matematika. Kegiatan workshop akan dilakukan pada siswa dan guru MI Al Iman dengan alasan sekolah memiliki masalah, yaitu banyak guru yang masih mengalami kesulitan cukup tinggi dalam menggunakan media atau aplikasi dalam pembelajaran matematika.

Pengabdian pada masyarakat ini bertujuan untuk meningkatkan keterampilan guru dalam menggunakan GeoGebra sebagai media pembelajaran matematika di SD/MI. Workshop dilaksanakan dengan metode diskusi, pengayaan materi matematika di SD dan workshop yang meliputi tutorial penggunaan aplikasi GeoGebra. Kegiatan pengabdian pada masyarakat ini dilaksanakan selama 4 bulan yang diikuti oleh 20 guru MI Al Iman.
\end{abstract}

Kata Kunci: GeoGebra, media, pembelajaran matematika 


\section{PENDAHULUAN}

Pesatnya perkembangan ilmu pengetahuan dan teknologi hingga saat ini telah mengantarkan umat manusia ke era kompetisi global di berbagai bidang kehidupan. Pada era globalisasi saat ini, ilmu pengetahuan dan teknologi semakin maju dan berkembang seiring dengan perkembangan zaman (Arifin, Trapsilasiwi, \& Fatahillah, 2016). Kebutuhan akan suatu konsep dan mekanisme belajar mengajar berbasis teknologi informasi dan komunikasi (TIK) menjadi tak terelakkan lagi. Berbagai aplikasi TIK sudah tersedia dalam masyarakat dan sudah siap menanti untuk dimanfaatkan secara optimal untuk keperluan pendidikan. Pada kondisi saat ini, TIK dalam pendidikan nantinya berfungsi sebagai gudang ilmu, alat bantu pembelajaran, fasilitas pendidikan, standar kompetensi, penunjang administrasi, alat bantu manajemen sekolah, dan sebagai infrastruktur pendidikan. Tujuan teknologi pembelajaran adalah membantu, memicu, dan memacu proses belajar peserta didik serta memberikan kemudahan atau fasilitas belajar (Surjono \& Gafur, 2010).

Perubahan pelaksanaan kegiatan belajar mengajar dapat teramati baik dari segi proses pembelajaran yang diterapkan di dalam kelas dan media pembelajaran yang digunakan. Proses pembelajaran saat ini tentunya juga harus disesuaikan dengan trend perkembangan zaman. Guru-guru SD/MI belum sepenuhnya menggunakan media pembelajaran matematika yang efektif, menarik, dan inovatif. Kebanyakan guru maupun siswa mengalami kesulitan dalam pembelajaran matematika terutama materi geometri. Berdasarkan hasil wawancara dengan kepala sekolah di MI Al Iman belum menerapkan media pembelajaran matematika yang menarik dan inovatif.

Salah satu teknologi yang mendukung pembelajaran matematika di SD/MI adalah GeoGebra. Geogebra dipilih karena GeoGebra dapat membantu siswa membangun pengetahuan baru dan menghubungkannya dengan pengetahuan sebelumnya, yang cukup konsisten dengan pendekatan pembelajaran yang konstruktif (Bhagat \& Chang, 2015). Selain itu, dapat meningkatkan kemampuan siswa untuk mengonseptualisasikan unsur-unsur matematika, sehingga dapat meningkatkan hasil pembelajaran (Emaikwu, Iji, \& Abari, 2015). 
Sebagai salah satu lembaga pendidikan yang mendidik calon tenaga edukatif, program studi Pendidikan Matematika FKIP UNTIDAR perlu berperan serta dalam membantu permasalahan keterbatasan guru dalam mengajar matematika menggunakan aplikasi atau media pembelajaran matematika yang sesuai dengan pembelajaran abad 21. Salah satu program yang perlu dilakukan adalah workshop penggunaan software GeoGebra sebagai media pembelajaran matematika, sebagai salah satu bentuk pengabdian pada masyarakat.

Berdasarkan analisis situasi yang dilaukakn dnegan observasi langsung dan wawancara, masih banyak permasalahan yang dialami oleh mitra. Permasalahan yang ditemui di lapangan, kebanyakan guru-guru belum pernah menggunakan aplikasi atau media pembelajaran matematika yang menarik dan inovatif.

Berdasarkan uraian di atas, dipertimbangkan perlu dilakukan kegiatan workshop penggunaan software geogebra sebagai media pembelajaran matematika bagi guru SD/MI. Harapannya, akan ada peningkatan keterampilan guru dalam menggunakan GeoGebra sebagai salah satu media pembelajaran matematika di SD/MI.

\section{METODE}

Khalayak sasaran kegiatan ini adalah guru-guru MI Al Iman Kota Magelang. Metode kegiatan yang diangggap tepat untuk menyelesaikan masalah tersebut adalah metode partisipasif, diskusi, penugasan, dan pendampingan. Pelaksanaan program pengabdian ini mencakup beberapa tahap kegiatan yakni tahap persiapan materi, tahap pelaksanaan program, dan tahap evaluasi kegiatan. Secara rinci, metode yang digunakan dapat dipaparkan sebagai berikut.

\section{Tahap Persiapan Materi}

Pada tahap ini dilakukan pengumpulan materi dari berbagai literatur tentang aplikasi pembelajaran yang mudah dan dapat digunakan bagi guru SD/MI. Pengumpulan materi dilakukan untuk mempersiapkan modul yang akan digunakan dalam kegiatan workshop. Setelah siap, maka disusun modul dan kemudian diserahkan 
kepada mitra untuk dipelajari. Setelah itu, dilakukan sosialisasi dan kesepakatan terhadap mitra terkait dengan waktu dan tempat pelaksanaan kegiatan.

\section{Tahap Pelaksanaan Program}

Tahapan pelaksanaan program "workshop penggunaan software geogebra sebagai media pembelajaran matematika" akan dilakukan sebagai berikut.

a. Tahap Identifikasi Kemampuan Awal Guru

Pada tahap ini guru akan diberikan beberapa daftar pertanyaan untuk mengetahui kemampuan guru dalam menggunakan aplikasi pembelajaran. Kegiatan ini dilakukan agar tim Pengabdian bisa mengetahui materi-materi yang harus diprioritaskan dalam pelaksanaan workshop.

b. Tahap Workshop

Pelaksanaan program dibagi menjadi tiga kegiatan, yaitu:

1) Pemberian materi mengenai media pembelajaran matematika

Pada kegiatan ini, TIM akan memberikan materi tentang media pembelajaran matematika, dilanjutkan dengan pembelajaran berbasis aplikasi GeoGebra. Materi akan dijelaskan berdasarkan landasan filosofis dan teoritis, serta kajian-kajian hasil riset mengenai proses pembelajaran matematika berbasis GeoGebra. Kegiatan ini akan dilaksanakan dalam 1 kali pertemuan, selama 100 menit.

2) Pendampingan pemanfaaan aplikasi pembelajaran

Pada tahap ini akan dilakukan pendampingan penggunaan media pembelajaran matematika menggunakan GeoGebra.

3) Simulasi Praktik mengajar di dalam kelas

Setelah guru selesai membuat media pembelajaran, selanjutnya dilakukan simulasi praktik mengajar di dalam kelas. Kegiatan simulasi dilakukan dengan tujuan untuk melakukan evaluasi keterampilan guru dalam memanfaatkan aplikasi pembelajaran GeoGebra. Kegiatan simulasi dilakukan selama 1 kali proses pembelajaran, dimana rekan-rekan guru yang tidak mensimulasikan akan beralih peran menjadi siswa.

\section{Monitoring dan Evaluasi Program}


Ada beberapa langkah monitoring dan evaluasi program dalam kegiatan ini.

a. Evaluasi proses dalam tiap akhir kegiatan, baik pemaparan materi maupun kegiatan simulasi praktik. Hal ini dilakukan untuk refleksi para peserta akan apa yang telah disajikan dan bagaimana para penyajinya. Demikian juga, tim pengabdi memberikan penilaian terhadap para peserta, baik kehadiran, keaktifan, maupun partisipasinya dalam setiap kegiatan.

b. Evaluasi produk. Evaluasi ini dilakukan dengan melihat kualitas media pembelajaran yang dibuat, serta keterampilan guru menggunakan aplikasi pembelajaran.

c. Evaluasi kebermaknaan, dengan memberikan kuesioner untuk melihat aspek kebermaknaan kegiatan yang dilakukan

\section{HASIL DAN PEMBAHASAN}

Workshop Penggunaan Software Geogebra merupakan salah satu Program Kemitraan Masyarakat yang dijalankan oleh Megita Dwi Pamungkas, S.Pd. dan Fadhilah Rahmawati, M.Pd. yang merupakan Dosen Pendidikan Matematika di Universitas Tidar. Workshop ini dilaksanakan selama 4 bulan dari tahap persiapan, pelaksanaan, dan evaluasi yaitu pada hari Senin, 27 Juli 2020 sampai hari Senin 10 Agustus 2020 yang dilaksanakan di MI Al Iman Kota Magelang. Adapun agenda dalam dua hari tersebut adalah sebagai berikut.

Pada hari pertama Senin, 27 Juli 2020, Workshop Penggunaan software Geogebra dilaksanakan di ruang kelas MI Al Iman Kota Magelang yang di hadiri oleh para Guru MI Al Iman Kota Magelang. Para Guru sangat antusias ketika pelaksanaan workshop berlangsung. Pada hari pertama, Bapak Megita Dwi Pamungkas, M.Pd. selaku pemateri membuka workshop ini dan memberikan informasi kepada Bapak/Ibu Guru bahwa program ini merupakan salah satu program kemitraan masyarakat untuk menjalankan salah satu Tridarma Perguruan Tinggi yaitu pengabdian kepada masyarakat yang salah satunya adalah memberikan pelatihan tentang penggunaan software Geogebra kepada Guru SD/MI terutama di MI Al Iman Kota Magelang dengan harapan software ini dapat berguna bagi para Guru untuk menunjang pembelajaran dalam materi geometri seperti bangun datar, bangun ruang, transformasi 
geometri, dan lain-lain. Setelah membuka workshop ini, Bapak Megita mempersilahkan kepada Bapak/Ibu Guru untuk membuka software Geogebra yang telah dikirimkan softwarenya sebelum pelaksanaan workshop ini.

Pada hari pertama ini masih banyak kendala di Bapak/Ibu Guru dikarenakan kesulitan dalam menginstal software ini sehingga mereka harus menginstal terlebih dahulu dan sambil mendengarkan penjelasan dari Pemateri. Pemateri memberikan materi penggunaan materi transformasi geometri dengan menggunakan software Geogebra, pada hari pertama beliau menjelaskan penggunaan materi pencerminan (refleksi) dengan menggunakan software tersebut sekaligus mempraktekkannya. Saat penjelasan Bapak dan Ibu Guru juga antusias dengan mencoba mempraktekkan dalam software geogebra di laptop masing-masing, terlihat bahwa Bapak/Ibu Guru masih asing dengan penggunaan software ini, tetapi mereka tetap semangat untuk berusaha agar bisa berhasil membuat suatu hasil pencerminan (refleksi) sesuai dengan hasil yang sesuai dengan menggunakan software Geogebra.

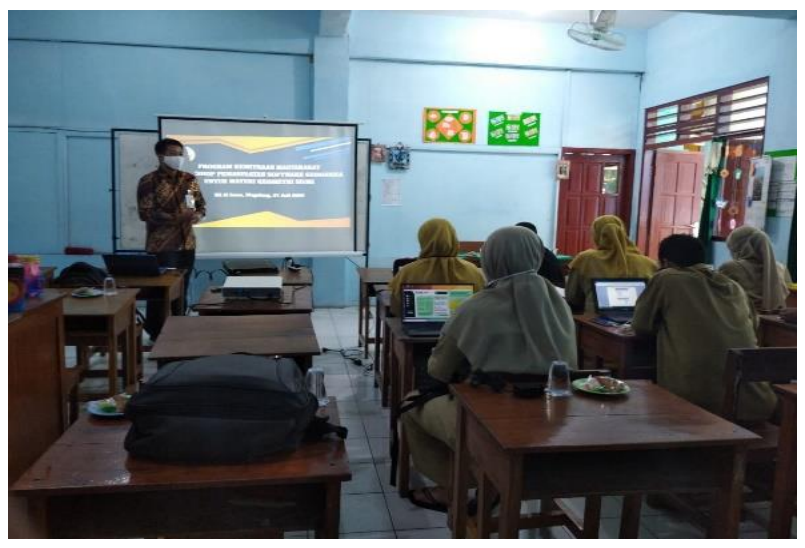

Gambar 1 Pelaksanaan Workshop GeoGebra Hari Pertama

Pada hari kedua, Kamis, 30 Juli 2020 Workshop Penggunaan software Geogebra kembali dilaksanakan di ruang kelas MI Al Iman Kota Magelang yang di hadiri oleh para Guru. Para Guru sangat antusias ketika pelaksanaan workshop berlangsung. Mereka sudah menyiapkan laptop masing-masing untuk mengikuti workshop kedua ini. Di hari kedua ini terlihat bahwa Bapak/Ibu Guru sudah tidak ada masalah lagi dalam penginstalan software ini, mereka sudah mulai bisa mengoperasikan software ini. Pada hari kedua ini, materi kembali disampaikan oleh Bapak Megita Dwi Pamungkas, M.Pd. Pada materi hari kedua masih melanjutkan 
materi transformasi geometri yaitu dilatasi dan rotasi. Beliau menjelaskan dengan sangat runtut bagaimana cara menemukan suatu dilatasu dari sebuah bangun datar, yang beliau gunakan adalah bangun ruang segitiga. Setelah menjelaskan dan mempraktekkan kemudian meminta Bapak/Ibu Guru untuk mengulang kembali apa yang telah disampaikan oleh beliau dengan mempraktekkan dengan software di laptop masing-masing. Sebagian besar Bapak/Ibu Guru sudah faham dengan yang dijelaskan dan dapat mencoba menerapkan dalam software tersebut.

Setelah materi dilatasi, kemudian Pemateri melanjutkan dengan menjelaskan tentang materi rotasi. Setelah menjelaskan, beliau meminta kembali kepada Bapak/Ibu Guru untuk mempraktekkan dalam software di laptop masing-masing kembali, sebagian besar dari para Guru sudah berhasil mempraktekkan materi rotasi dalam software geogebra tersebut. Terlihat bahwa di hari kedua ini antusias dari Bapak/Ibu Guru sangat bagus, mereka masih semangat untuk menerima materi tentang penggunaan software geogebra ini. Kemudian agar tidak lupa dengan materi yang telah dijelaskan para Guru mencatat dalam buku masing-masing agar tidak lupa dengan materi yang telah dijelaskan.

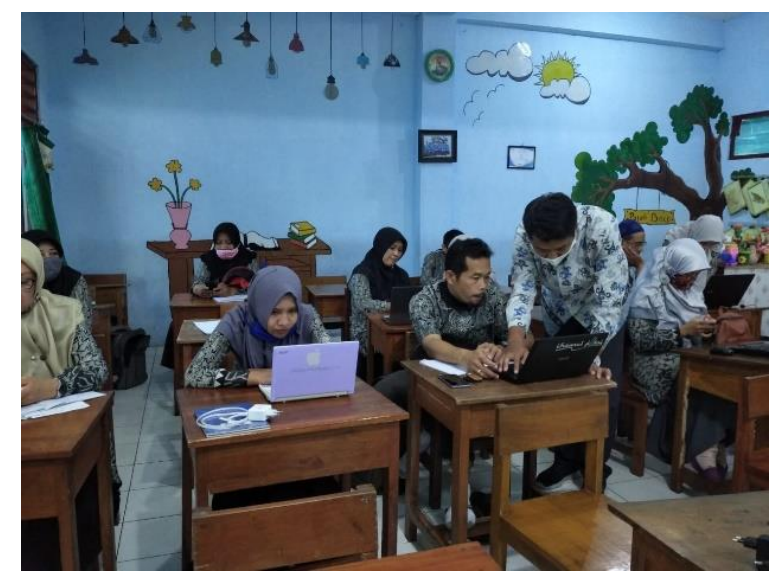

Gambar 2 Pelaksanaan Workshop GeoGebra hari Kedua

Pada hari ketiga, Workshop Penggunaan software Geogebra dilaksanakan di ruang kelas MI Al Iman Kota Magelang yang di hadiri oleh para Guru MI Al Iman Kota Magelang dan Pemateri yaitu Megita Dwi Pamungkas, M.Pd. dan Fadhilah Rahmawati, M.Pd. Setelah sedikit menjelaskan materi tentang transformasi geometri (pengayaan), Pemateri kemudian memberikan post test kepada Bapak/Ibu Guru agar 
lebih paham lagi dengan materi-materi yang telah dijelaskan pada hari pertama maupun hari kedua.

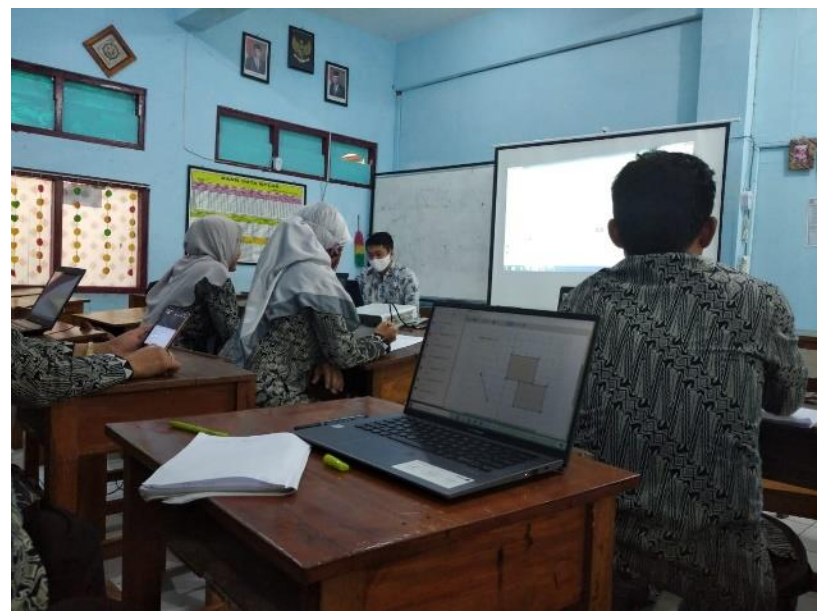

Gambar 3 Pelaksanaan Workshop GeoGebra hari Ketiga

Secara keseluruhan, kegiatan pengabdian ini dilakukan sebanyak 9 kali dengan rincian sebagai berikut.

Tabel 1. Rangkaian Kegiatan Pengabdian

\begin{tabular}{|c|l|}
\hline Tanggal & \multicolumn{1}{|c|}{ Kegiatan } \\
\hline 18 Mei 2020 & $\begin{array}{l}\text { Koordinasi Internal tim pengabdian untuk membagi tugas } \\
\text { dalam menyiapkan kebutuhan pelatihan (materi, } \\
\text { perlengkapan, akomodasi, administratif) }\end{array}$ \\
\hline 25 Mei 2020 & $\begin{array}{l}\text { Koordinasi eksternal dengan MI Al Iman dalam pemilihan } \\
\text { peserta, penyediaan tempat pelatihan serta penyusunan } \\
\text { konsep materinya }\end{array}$ \\
\hline 27 Juli 2020 & Melakukan pengabdian pertemuan hari pertama \\
\hline 30 Juli 2020 & Melakukan pengabdian pertemuan hari kedua \\
\hline 10 Agustus 2020 & Melakukan pengabdian pertemuan hari ketiga \\
\hline 25 Agustus 2020 & $\begin{array}{l}\text { Berpamitan dan memberikan sertifikat pelatihan/workshop } \\
\text { kepada peserta }\end{array}$ \\
\hline
\end{tabular}

\section{Peningkatan Kemampuan Guru dalam Menggunakan GeoGebra sebagai Media Pembelajaran Matematika}

Hasil pengabdian menunjukkan bahwa terjadi peningkatan kemampuan guru dalam membuat media pembelajaran matematika dengan menggunakan GeoGebra. Hal ini dapat dilihat dari tugas akhir yang sudah dikerjakan Bapak/Ibu guru selama pengabdian dilaksanakan. 
b. 90 derajat berlawanan arah jarum jam

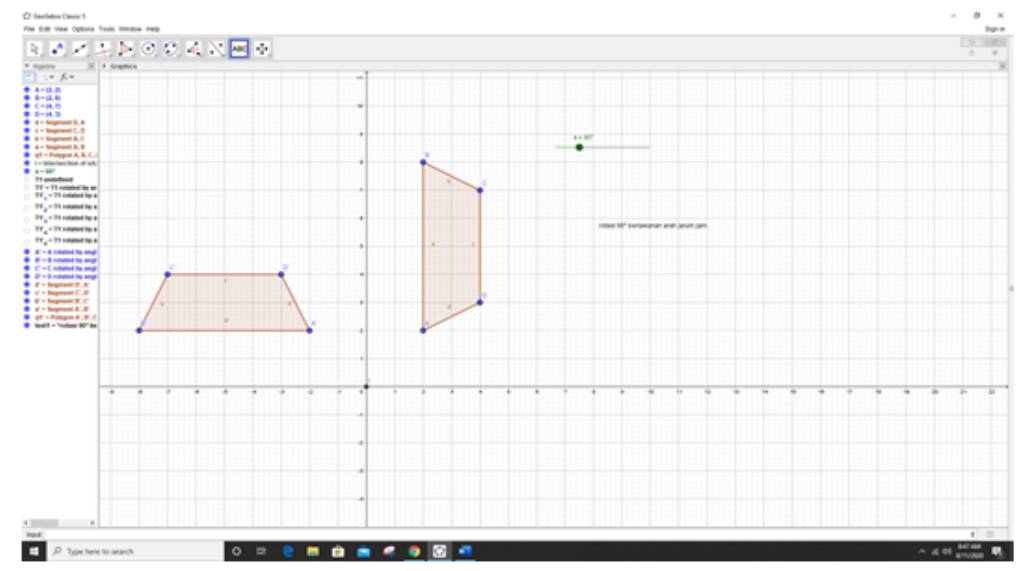

Gambar 4. Tampilan Tugas Akhir GeoGebra sebagai Media Pembelajaran

\section{KESIMPULAN}

Workshop dilaksanakan dengan metode ceramah, diskusi, pengayaan materi dan pelatihan yang meliputi tutorial dan tugas akhir kegiatan pengabdian pada masyarakat ini dilaksanakan selama 4 bulan mulai dari pembuatan proposal sampai dengan penyusunan laporan akhir. Berdasarkan hasil dan pembahasan pada pelaksanaan pengabdian yang telah dilakukan, bahwa kemampuan guru dalam rangka menyiapkan media pembelajaran matematika menggunakan GeoGebra meningkat. Selain itu dihasilkan juga modul penggunaan GeoGebra bagi guru sekolah dasar.

Berdasarkan temuan data-data pengabdian, dosen-dosen maupun guru dapat melakukan inovasi kegiatan pelatihan penggunaan aplikasi sebagai media pembelajaran matematika. Tentunya, media pembelajaran tersebut harus disesuaikan dengan karakteristik siswa dan lingkungan belajarnya.

\section{DAFTAR PUSTAKA}

Arifin, Z., Trapsilasiwi, D., \& Fatahillah, A. (2016). Analisis kemampuan komunikasi matematika dalam menyelesaikan masalah pada pokok bahasan sistem persamaan linier dua variabel siswa kelas viii-c smp nuris jember. Jurnal Edukasi, 3(2), 9-12.

Bhagat, K.K. \& Chang, C.Y. (2015). Incorporating GeoGebra into Geometry learning-A lesson from India. Eurasia Journal of Mathematics, Science \& Technology Education, 11(1), 77-86. doi:10.12973/eurasia.2015.1307a 
Emaikwu, S. O., Iji, C. O., \& Abari, M. T. (2015). Effect of Geogebra on Senior Secondary School Students' Interest and Achievement in Statistics in Makurdi Local Government Area of Benue State, Nigeria. Journal of Mathematics (IOSRJM), 2(3), 14-21

Surjono, H. D., \& Gafur, A. (2010). Potensi pemanfaatan ICT untuk peningkatan mutu pembelajaran SMA di kota Yogyakarta. Cakrawala Pendidikan, 2(2) 